\title{
Anger and depression
}

\section{Fredric N. Busch}

\begin{abstract}
SUMMARY
A series of psychoanalytic theorists and clinicians have suggested that conflicts about anger play a central role in the development of depression. Research data have supported the notion that patients struggle with the experience and expression of angry feelings. Anger in people with depression often stems from narcissistic vulnerability, a sensitivity to perceived or actual loss or rejection. These angry reactions cause intrapsychic conflicts through the onset of guilt and the fear that angry feelings will disrupt relationships. These conflicts lead to anger being directed inwards, further lowering self-esteem, creating a vicious cycle. Defence mechanisms that are triggered, including passive aggression, reaction formation, denial and identification with the aggressor, are ineffective at managing these conflicts and further prevent the appropriate expression of anger. This article discusses how to identify and detoxify angry feelings and fantasies using a psychodynamic approach.
\end{abstract}

\section{DECLARATION OF INTEREST}

None.

Anger has been thought to play an integral role in depression since the early stages of psychoanalytic theorising about this disorder (Busch 2004). The oversimplified concept of depression as 'anger directed inwards' was a commonly held belief over many years in psychiatry and gained a foothold in the broader culture. As will be described in much greater depth below, psychoanalytic theorists and clinicians have viewed anger as a significant source of conflict for patients prone to depression, triggering intense guilt and self-criticism. Identification of the often unconscious anger and its sources, including rejection and loss, leads to an increase in its tolerability and to diminished guilt and depression.

With the emergence of other types of treatment, psychoanalytic conceptualisations of depression and anger have become viewed as outmoded. Cognitive-behavioural approaches do not conceive anger as a core contributor to depression, and addressing anger is not considered central to treatment (Schuyler 2003; Kuyken 2005). From the psychopharmacological perspective, anger may be a symptom of depressive disorders to be addressed with medication, but is not seen as aetiological. Many clinicians, however, continue to view anger as a significant clinical factor in the treatment of their patients.

Anger in patients with depression can vary clinically, from individuals who deny angry feelings to those who display significant irritability and aggressive behaviour. Neither of these presentations should be viewed as arguments against psychoanalytic models of conflicted and self-directed anger. Patients who deny angry feelings are often unable to tolerate them and may well be self-critical. Patients may be able to experience intense anger with regard to particular fantasies, people or situations, but inhibited about acknowledging it in others. Some patients who are irritable or aggressive have intense guilt about the way they express their anger.

More broadly, then, many patients with depression have difficulty with modulation and management of angry feelings and fantasies. In addition, hostility, a negative evaluation of others often accompanied by a wish that they be harmed, can create guilty feelings. Hostility can be related to devaluation of others, a defence employed by patients with depression to increase their self-esteem. This defence, however, disrupts interpersonal relationships and prevents others from being viewed as potential sources of support. Rage, or explosive and uncontrolled anger, can be followed by intense bouts of self-criticism and depression, and can be particularly damaging to relationships with others. Helping patients to modulate and control the interpersonal disruptions and adverse impact of their anger and rage is an important part of their treatment.

This article reviews the limited research available regarding the link between anger and depression, describes psychoanalytic models of depression, and delineates psychodynamic approaches for addressing anger and depression. A fictitious case vignette is presented to demonstrate how anger can be understood and worked with in the clinical situation.

\section{Research on anger and depression}

Research studies on the link between anger and depression have indicated either an increase in outwardly directed anger or a greater degree of suppressed anger in patients with depression (Luutonen 2007). Epidemiological studies have found depression to be associated with an increased risk of violent behaviour (Swanson 1990), including towards a spouse (Pan 1994; Feldbau-Kohn 1998). Koh and colleagues (2002) found that patients
Fredric N. Busch is Clinical Associate Professor at Weill Cornell Medical College and a faculty member of the Columbia University Center for Psychoanalytic Training and Research. His publications and research have focused on the links between psychoanalysis and psychiatry, including psychodynamic approaches to specific disorders, psychoanalytic research, and psychoanalysis and medication Correspondence Dr Fredric N. Busch, 10 East 78th Street, New York, NY 10075, USA. Email: fnb80@ aol.com 
with depression demonstrated a greater amount of total anger and anger expression than patients with anxiety disorders, somatoform disorders and healthy controls. A study by Schless et al (1974) of in-patients with depression showed that the degree of anger correlated with the severity of depression, but that the patients expressed anger outwards or turned it inwards in equal numbers. Anger and hostility were found to diminish with effective antidepressant treatment (Fava 1993).

Other studies support the notion that anger directed towards the self is linked with depression. Becker \& Lesiak (1977) found that in clinic outpatients, severity of depression correlated with covert hostility, including guilt, resentment, irritability and suspicion, but not with overt hostility. Wolfersdorf \& Kiefer (1998) showed that, compared with healthy controls, in-patients with depression had increased levels of inhibited aggression and covert hostility, but did not express aggression. Goldman \& Haaga (1995) found increased anger, suppressed anger and fear of expressing anger in self-reports of out-patients with depression compared with controls without depression. Patients in part feared retaliation or rejection if they expressed anger. Brody and colleagues (1999) found more suppressed anger in individuals recovered from depression than in healthy controls, along with an increased fear that expressing anger could damage relationships.

All of these studies suggest that anger is a prominent feature of depression. As noted above, both expressed and suppressed anger can be a source of conflict and become self-directed. Therefore, it is important to understand and address how anger and depression may interact.

\section{Psychoanalytic theories of depression}

From the early days of psychoanalysis, theoreticians and clinicians have suggested that difficulties coping with anger are related to depression onset and persistence (Busch 2004). Abraham (1911) was the first to conceptualise depression as self-directed anger. He noted a propensity towards hatred in patients with depression, based on temperament or early experience. This excess anger creates guilt and anxiety, and becomes repressed and projected. The resulting belief that others hate the patient leads to the presumption that they are somehow inadequate or deficient, lowering self-esteem. Abraham (1924) subsequently postulated that individuals with depression suffer from low self-esteem and anger secondary to a traumatic rejection, either in early or later life.

In Freud's (1917) view, depression results from a fantasised or actual loss of an individual towards whom the patient experienced ambivalent feelings. To deal with the loss, the patient internalises an aspect of that individual. However, the anger at that person now becomes directed towards the part of the self identified with that individual, leading to self-criticism, reproach and depression.

Adding to Abraham's concept of narcissistic vulnerability, Rado (1928) described how patients with depression have a sensitivity to disappointments and rejection, reacting to relatively minor disappointments with intense feelings of inadequacy and anger. He also suggested that in the development of depression a split in perception occurs, in which the self or others are viewed as all good or all bad. The good qualities become internalised as what the patient hopes to be, the ego ideal, whereas the bad aspects become identified as part of the self, as in Freud's model. The ego then comes under attack by the superego, or conscience, for failure to live up to the ego ideal.

Klein $(1935,1940)$ described the depressive position, which begins when the child recognises the mother as a 'whole object', rather than split into good and bad, and becomes fearful that his destructive fantasies could damage the mother. The child then struggles with guilt about aggressive feelings. Klein viewed depressive states as a reactivation of the depressive position, with patients believing that their aggression and greed have damaged their 'love objects' (Gabbard 2000). The individual with depression, then, has not been able to integrate or tolerate conflicts between loving and angry feelings towards love objects, creating persistent guilt. The fear that good objects have been destroyed leads to a fantasy of being alone with bad objects, adding to depressive feelings.

Jacobson $(1954,1971,1975)$ conceptualised depression as arising from a lack of self-acceptance and of emotional understanding from parents, triggering ambivalence, low self-esteem and guilt in the child. Anger at the parent becomes directed at the self in order to protect the parent and prevent the self from acting in a hostile manner. A severe superego results, and the person criticises themselves for characteristics or attitudes resembling the parents. A strong ego ideal and a tendency to idealise others develop to counteract low self-esteem. The resulting overexpectation of self and others, however, triggers recurrent disappointments.

Brenner $(1975,1979)$ saw depression as resulting from symbolic castration as a punishment for sexual and aggressive wishes. The individual experiences aggression towards the person viewed as the source of this disempowerment, but the anger becomes self-directed as the individual becomes ingratiating towards the feared other. 


\section{Defence mechanisms in depression}

Individuals with depression may unconsciously attempt to manage anger and protect the loved other from angry feelings and fantasies through the employment of particular defence mechanisms, but the operation of these mechanisms often acts to exacerbate depression. Defence mechanisms found in clinical observations and research studies of people with depression include denial, projection, passive aggression, reaction formation and identification (Bloch 1993).

Denial keeps the individual's anger and other conflicted feelings out of consciousness. In depression, the mechanism is employed primarily to deny hostility. Use of denial frequently exacerbates depression, as anger becomes directed towards the self, and patients are not able to use their angry feelings effectively to address interpersonal problems.

In projection, as per Abraham (1911), conflicted anger towards others is denied and seen as being expressed by others towards the self. As Abraham notes, this leads the person to feel increased rejection and a further reduction in self-esteem.

In passive aggression, anger is expressed indirectly via withholding behaviours. These behaviours typically exacerbate interpersonal problems, as others become angry at the individual.

In reaction formation, anger is denied and counterbalanced by increased efforts to help others. Interpersonal and intrapsychic issues that are creating the anger, however, remain unaddressed, further fuelling rageful feelings and fantasies. As noted above, identification can be employed to reduce a sense of loss of an important other, but angry feelings towards the other can become directed towards the self (Freud 1917).

In identification with the aggressor, the person links their self-image with someone who is aggressive and has made the person or others feel disempowered. Although this may help the individual to gain feelings of power and control, it frequently triggers guilty feelings about wishes to control or abuse others.

\section{Psychodynamic formulation for depression}

Employing theoretical, clinical and research perspectives, Rudden et al (2003) and Busch et al (2004) developed a core psychodynamic formulation for depression. Individuals prone to depression are viewed as having a high level of sensitivity to loss or rejection, broadly referred to as narcissistic vulnerability. The sensitivity develops in the context of early life experiences involving feelings of disappointment and helplessness, which become interpreted as signs of inadequacy, unlovability or

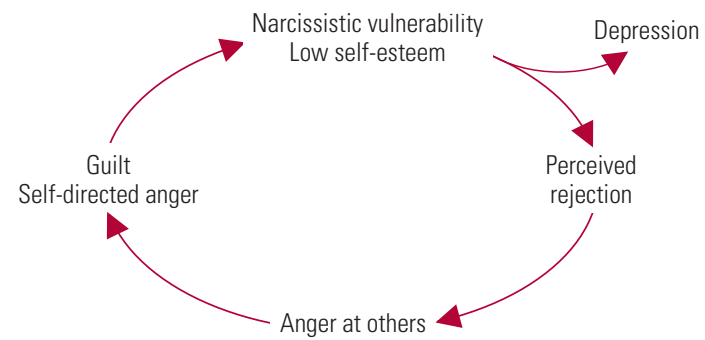

FIG 1

Vicious cycles in depression: narcissistic vulnerability and anger. Reprinted, with permission, from Busch (2004): (C) 2004 American Psychiatric Publishing, Inc.

damage. In addition, these children often think that they are overly needy, which can trigger feelings of powerlessness and shame. The sensitivity becomes a part of these individuals' identity, broadly affecting their psychological functioning, and subsequent failures, losses or rejections are viewed as further evidence of inadequacy and damage.

Along with sadness and unlovability, disappointment and rejection often trigger angry reactions at the people seen as the source of these painful experiences. As described above, this anger triggers guilty feelings and defence mechanisms intended to protect the needed other. The anger becomes selfdirected, further lowering self-esteem, creating a cycle of narcissistic vulnerability and anger (Fig. 1). In a second vicious cycle, low self-esteem is seen as causing a compensatory idealisation of the self and others. However, these idealised expectations invariably lead to disappointment and devaluation, further lowering self-esteem (Fig. 2). Angry feelings and fantasies are connected with the devaluation of the self and others that occurs in this context. Although narcissistic vulnerability is seen as primary in these formulations, a constitutional or developmentally triggered angry reactivity, as per Abraham (1911), could also be seen as central.

\section{Psychodynamic approaches to depression}

\section{Overview}

Psychodynamic treatment of depression differs from traditional psychoanalytic approaches in that

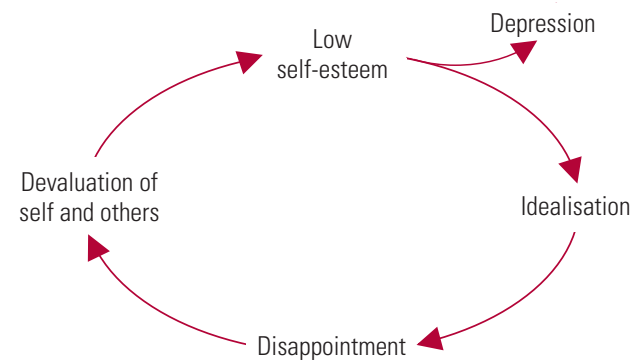

FIG 2

Vicious cycles in depression: low self-esteem and idealisation/devaluation. Reprinted, with permission, from Busch (2004): @ 2004 American Psychiatric Publishing, Inc. 
its focus is on the symptoms and dynamics of a particular disorder, as opposed to a more generalised focus on the individual's 'neurosis' and broad range of functioning. A focused psychodynamic approach, like traditional psychoanalytic approaches, allows the person to take the lead in determining the content of a given session, but it always brings them back to the symptoms and dynamics of their disorder.

Psychodynamic treatment of depression can be employed either as a shorter-term intervention (3-6 months) targeting the reduction of depressive symptoms, or as longer-term treatment (6 months to 2 years) that addresses character problems and other vulnerabilities to depression.

The model for this approach was in part derived from panic-focused psychodynamic psychotherapy, which has demonstrated efficacy as a twice-weekly, 24-session intervention in the treatment of panic disorder (Milrod 1997, 2007). Treatment has three phases. It begins by establishing a therapeutic alliance and frame, exploring the circumstances, feelings and fantasies surrounding depression onset, and identifying developmental determinants. As exploration proceeds, these factors are linked to the core dynamics of depression as elucidated

\section{BOX 1 Phase 1: the beginning of treatment}

The therapist examines with the patient the depressive symptoms and their context to uncover developmental determinants, identify areas of intrapsychic conflict and begin understanding the meanings of the symptoms.

\section{Areas of focus}

1 Establishing the treatment frame and engaging the patient in a therapeutic alliance

2 Exploring the stressors, perceptions and feelings accompanying the onset of the depression

3 Linking item 2 above to the core dynamics of depression, in the present and during the patient's development:

a narcissistic vulnerability based on experiences/perceptions of loss, illness, rejection, separation or difference

b reactive, conflicted anger (including feelings of envy, blame, jealousy, a wish for revenge), often ultimately directed towards the self

c guilt, resulting from anger; shame, resulting from a sense of inadequacy or damage related to the experiences or perceptions mentioned in item $3 a$

d compensatory idealisation of self or others, followed by disappointment and devaluation

e defences employed in coping with painful affects

Expected responses

1 Reduction in depressive symptoms

2 Tentative formulation of central themes and dynamisms offered to the patient

3 Establishment of a good working relationship

Reprinted, with permission, from Busch (2004): (c) 2004 American Psychiatric Publishing, Inc.
BOX 2 Phase 2: the middle of treatment

To reduce the patient's vulnerability to depression, the dynamisms described in the text are understood from many vantage points, as the patient has experienced them internally and in fantasy, in relation to significant others in the present and past, and in their emergence with the therapist. Greater understanding permits easier identification of depressive constellations when they emerge and a greater sense of control in managing them.

Areas of focus

1 Addressing, as they emerge, conflicted feelings and fantasies related to the central dynamics with significant others in the present and past

2 Addressing related feelings and fantasies in the transference

3 Greater understanding of and control over these conflicts by exploring their presence in a variety of forms and contexts

\section{Expected responses}

1 Reduced vulnerability of self-esteem to loss, disappointments, criticism

2 Increased tolerance of anger, accompanied by greater recognition of this affect and of the tendency to turn it against the self

3 Reduction in guilt and self-punishing behaviours

4 Improved interpersonal relationships, less contaminated by shame and by idealisation or devaluation

Reprinted, with permission, from Busch (2004) (c) 2004 American Psychiatric Publishing, Inc

in the theory above: narcissistic vulnerability, conflicted anger, guilt, compensatory idealisation and devaluation, and defences (Box 1). In phase II, aimed at reducing vulnerability to depression, these dynamics and conflicts are explored as they emerge in relationships, including those with the therapist. The goals of this phase include reduced narcissistic vulnerability and increased tolerance of anger, with more effective engagement in relationships (Box 2). In the termination phase, rejection sensitivity and reactive anger are explored as they emerge in ending the relationship with the therapist, with a goal of gaining additional understanding and control over guilt, anger and narcissistic vulnerability (Box 3).

\section{Exploration of anger}

In psychodynamic treatment of depression, an important aspect of therapy is to elucidate angry feelings and fantasies. Reviewing current stressors and those surrounding the onset of depression can be useful in identifying specific fantasies. Frequently, individuals have experienced a narcissistic injury, typically a perceived or actual loss or rejection, 
BOX 3 Phase 3: the termination of treatment

Termination provides a crucial opportunity for further work with the dynamics of depression, especially as they emerge in the transference.

\section{Areas of focus}

1 Understanding feelings about the loss of the therapist and the ending of treatment

2 Coping with the sense of narcissistic injury in fantasies of a continued relationship with the therapist

3 Anger with the therapist over termination and the limitations of treatment

Expected responses

1 Possible briefly intensified feelings as termination approaches and the patient contends with a powerful resurgence of feelings about loss and separation

2 Increased capacity to cope with loss and narcissistic injury

3 More effective use of anger, with less self-direction

4 Reduced guilt and need for self-punishment

Reprinted, with permission, from Busch (2004): (C) 2004 American Psychiatric Publishing, Inc.

which causes conflicted angry reactions towards the person or persons they perceive to be the source of this injury. In addition to recent stressors, it is important to explore past experiences that triggered feelings of rejection and anger, as early traumatic losses or separations typically play an important role in the development of narcissistic vulnerability and conflicted anger.

The therapist must be aware that individuals often deny angry feelings and have difficulty tolerating them. The emergence of the person's discomfort in exploring angry fantasies provides an opportunity to identify how anger becomes directed towards the self. Possible reactions include intense guilt, expectations of punishment and anxiety. The therapist's non-judgemental stance is essential in exploring angry feelings, as individuals anticipate that the therapist will be critical in the same way that they feel about their anger and will therefore punish them. This perception of the therapist can be a manifestation of the transference, in which organising, unconscious influences of early, formative relationships emerge in the relationship with the therapist. Work with the transference is a valuable component of psychoanalytic treatment, as individuals can explore their conflicts in the immediacy of the therapeutic relationship.

\section{Impact on relationships}

People with depression and conflicts with anger tend to have difficulties with assertiveness in their relationships. Low self-esteem, guilt and fear of punishment often lead them to yield to others in ways that further exacerbate their low self-esteem. Such people have a lack of practice at expressing their anger and when they do so, may express it in a passive or overly aggressive manner. As assessed by Goldman \& Haaga (1995) and Brody et al (1999), patients fear that expression of their anger may damage important relationships. Identification and increased tolerance of these feelings can allow individuals to effectively express their assertiveness and set better boundaries and limits with others. The improvement in relationships provides a positive feedback with regard to self-esteem.

\section{Case vignette: $\mathrm{Mr} \mathrm{A}$}

The following vignette illustrates the elucidation of conflicted anger and its relationship to depression.

Mr A, a 26-year-old working in a marketing agency, presented with symptoms of major depression related to conflicts with his girlfriend. He felt she was not emotionally responsive enough, for example by being unable to recognise when he was upset or to adequately comfort him. On occasion she would be critical of his intelligence or his appearance. Mr A felt deeply hurt by these comments and, demonstrating narcissistic vulnerability, was preoccupied by them long after she said them. He did consider the possibility that he might be overreacting to these slights. His girlfriend wanted to continue the relationship, but Mr A, feeling rejected, decided to end it.

In exploring his history, Mr A described longstanding feelings of rejection by his mother. When Mr A was 4 years old, his mother became increasingly preoccupied with a political cause. As Mr A's father was a busy lawyer, his mother's increased involvement in her organisation led the boy to spend much of his time at home with just his nanny. Mr A got along well with his father when he was at home, but his mother became irritable and critical, often preoccupied with other matters. Mr A had little recollection of anger at his mother, recalling primarily longing and wishes for approval. Efforts to get his mother to pay more attention to him, however, such as imploring her to spend more time with him, would be met by angry reactions. He later developed the fantasy that she rejected him because he was 'not clever', having been aware from his mother's comments that she spent much of her time with professors from the university. In therapy, $\mathrm{Mr} \mathrm{A}$ became able to acknowledge and explore his anger at his mother, but this triggered significant discomfort.

\section{Extract 1}

Mr A I realise that I'm very angry at my mother, but it's very difficult to talk about it.

Therapist What makes it so hard?

MrA It feels way too harsh.

Therapist Do you think you feel guilty or embarrassed about having these feelings towards her?

Mr A Yes, I do. I mean, she basically rejected me to pursue these other interests. I loved her and wanted to be with her. Maybe she was doing the best that she could do. She went through a lot when she was growing up. 
Therapist Well, she certainly may have been affected by her background, but I think it's still important to understand your feelings towards her. Also, you may be emphasising her background because you feel guilty about how angry you are.

Mr A I also think you'll see me as an unforgiving and harsh person.

Therapist It seems as if you expect me to feel critical of your feelings just as you do.

Mr A It's hard to admit that sometimes these feelings are really strong. I think that what I really want is some kind of retribution. Parents who reject their children deserve to be punished for what they've done.

This vignette demonstrates progress in the identification and expression of angry feelings, conflicts about these feelings, and the process by which anger at others becomes directed towards the self. Mr A struggles with expressing his anger and acknowledges feeling guilty about it. He deals at first with his conflict by stepping back from his anger, a defence known as undoing, stating that maybe his mother could not help her behaviour. He then directs his anger inwards, becoming selfcritical, and projects it onto the therapist, whom he views as critical of him. Mr A regularly experiences this cycle internally, which results in feelings of guilt, rejection and inadequacy. The therapist maintains a non-judgemental stance, encouraging $\mathrm{Mr} \mathrm{A}$ to explore his intense aggression. After feeling safer that his therapist is not critical, Mr A takes another step, acknowledging that his angry fantasies take the specific form of revenge against his mother, and his self-criticism diminishes.

In addition to his guilty feelings, $\mathrm{Mr} \mathrm{A}$ is terrified that if others saw him as angry, they would leave him, as his mother had 'left' him to pursue her political cause. Helping Mr A to acknowledge this fear is a crucial step towards working with him about his guilt, as well as his pessimistic view that he could expect rejection by others. Working with his expectations of punishment in the transference helps Mr A to understand more directly how this fear can wrongly emerge with important people in his life, as he recognises that the therapist is not actually critical of him.

\section{Competitive feelings and aggression}

For people with depression, competitive feelings and behaviour may be intensified in response to narcissistic injury as a means of defeating a rival to gain love and attention. Competitive wishes, however, are often linked with conflicted aggression, leading to denial, guilt and self-criticism. Identifying these wishes and rendering them less toxic can aid in assertiveness and in increasing self-esteem.
Several sessions after the conversation related in extract 1, exploration of Mr A's anger entered a new phase. Early in his treatment, his awareness or expression of competitive wishes typically triggered intense guilt. As he began feeling less conflicted, Mr A, who was having increasing success at his advertising job, became aware of his enjoyment in getting ahead of his competitors. He would say with a smile that he had 'won' when describing a particular instance of outdoing a colleague, for example by getting a new account. At that point, however, Mr A would become anxious.

Extract 2

Therapist You look very uncomfortable.

Mr A I feel badly about what I said. It was mean.

Therapist What was mean about it?

Mr A Well, I didn't tell you that I not only enjoyed my winning, but I like the other person losing. I'm a terrible person. Now I'm sure you'll think negatively of me.

Therapist Clearly you're very self-critical about this. I think we need to help you be more accepting of your own feelings and wishes. I'm not aware of your actually acting in a mean way.

Mr A Oh no. Not at all. I would never say anything to them about it.You're right. That makes me feel better.

Individuals with depression, owing to their severe superego, often equate thought and action. In this extract, Mr A was able to gain some recognition that his vengeful and competitive fantasies were not actually enacted in his behaviour, that they did not cause direct harm to others. Over time, Mr A became increasingly aware of a fantasy of turning the tables on others and having power over them. He would make them suffer with longing in the same way that he felt with his mother. Thus, he enjoyed defeating them. At this point, Mr A was demonstrating identification with the aggressor, in which he identified with his mother's hurtful behaviour towards him. After experiencing this link, feelings of guilt and self-criticism were triggered. Thus, he experienced the first vicious cycle of depression described in Fig. 1, in which his narcissistic vulnerability triggered an angry reaction, followed by guilt and self-criticism, with a further decrease in self-esteem. As in extract 1, Mr A's transferential experience allowed him to see the difference between an expected response and the therapist's non-judgemental reaction.

His guilt became more acute as his mother had increasing difficulties in her own life. She was excluded from the organisation she was involved in and felt isolated, after which she sought more time with her son. At first he agreed to increased contact with her even though he did not want to, 
feeling she had not supported him when he had had problems. It emerged, however, that his behaviour represented a reaction formation with respect to vengeful feelings towards his mother. He had experienced the fantasy: 'I'm going to make her wait just like she did to me. Let's see how she likes it.' This fantasy triggered intense guilt and a willingness to accept her visits without limitations. Then he would become depressed when his mother visited and made her usual criticisms. The realisation in therapy of this fantasy of turning the tables on his mother helped him to recognise and better tolerate his wish to punish her. In this context, Mr A's selfesteem improved and he became able to set better limits with her: he was able to tell her that unless she behaved in a less hurtful manner he would be unwilling to get together.

\section{Termination}

Termination of therapy provides another opportunity to address a person's conflicted anger. Typically, angry fantasies towards the therapist intensify at this point, because ending the treatment is often experienced as a narcissistic injury: individuals must confront fantasies of maintaining a special relationship with the therapist; they may sometimes experience a resurgence of depressive symptoms as they contend with this loss.

As termination approached, Mr A described fantasies of getting together with his therapist at his home or going to dinner. Although he recognised these experiences were not possible in the therapeutic relationship, he was also aware that he felt disappointed and angry that they could not happen. There was a resurgence of feelings of being rejected, as he felt with his mother, with the onset of mild depressive symptoms. Mr A, however, felt tremendous relief in being able to express these intense feelings: 'My mother would just get furious at me if I talked to her about this.' By the end of treatment, his ability to express such feelings allowed a shift from anger directed inwards to an effective expression of them. New relationships that he developed followed a different model of give and take, and communication about feelings based more on the therapeutic relationship.

\section{Role of medication in psychodynamic treatment of anger and depression}

Psychodynamic treatment of depression, then, provides a powerful tool in helping individuals identify and detoxify conflicts about anger. By interrupting the vicious cycle of the feelings described earlier, and diminishing self-criticism, increased tolerance of anger can lead to improved self-esteem and diminished depression. Psychodynamic psychotherapy can be readily integrated with medication. Although psychodynamic psychotherapy may be employed as a sole treatment for mild to moderate depressive symptoms, medication should be strongly considered if the person is suffering severely, has a significant disruption in functioning or expresses suicidal ideation. In such cases, medication can allow the individual to participate more effectively in psychotherapy through improvements in concentration and motivation.

As discussed, there is evidence that psychodynamic vulnerabilities to depression persist even after the resolution of depressive symptoms. Thus, ongoing psychodynamic treatment may help reduce vulnerability to recurrences.

Although the limited studies of treatment of depression with psychodynamic psychotherapy have shown promising results (Churchill 2001; Leichsenring 2001; Abbass 2006; Knekt 2008), further research will help to clarify the role this approach can best play in treatment of depression and conflicted anger.

\section{References}

Abbass AA, Hancock JT, Henderson J, et al (2006) Short-term psychodynamic psychotherapies for common mental disorders. Cochrane Database of Systematic Reviews; 4: CD004687.

Abraham K (1911) Notes on the psycho-analytical investigation and treatment of manic-depressie insanity and allied conditions. In Selected Papers on Psychoanalysis, 137-56. Hogarth Press, 1927.

Abraham K (1924) A short study of the development of the libido, viewed in the light of mental disorders. In Selected Papers on Psychoanalysis, 418-501. Hogarth Press, 1927

Becker EW, Lesiak WJ ( 1977) Feelings of hostility and personal control as related to depression. Journal of Clinical Psychology; 33: 654-7.

Bloch AL, Shear MK, Markowitz JC, et al (1993) An empirical study of defense mechanisms in dysthymia. American Journal of Psychiatry; 150: $1194-8$.

Brenner C (1975) Affects and psychic conflict. Psychoanalytic Quarterly; 44: 1-28.

Brenner C (1979) Depressive affect, anxiety and psychic conflict in the phallic-oedipal phase. Psychoanalytic Quarterly; 48: 177-97.

Brody CD, Haaga DAF, Kirk L, et al (1999) Experiences of anger in people who have recovered from depression and never-depressed people. Journal of Nervous and Mental Disease; 187: 400-5.

Busch FN, Rudden M, Shapiro T (2004) Psychodynamic Treatment of Depression. American Psychiatric Press.

Churchill T, Hunot V, Corney R, et al (2001) A systematic review of controlled trials of the effectiveness and cost-effectiveness of brief psychological treatments for depression. Health Technology Assessment; 35: $1-173$

Fava M, Rosenbaum JF, Pava JA, et al (1993) Anger attacks in unipolar depression, Part 1: Clinical correlates and response to fluoxetine treatment. American Journal of Psychiatry; 150: 1158-63.

Feldbau-Kohn S, Heyman RE, O'Leary K (1998) Major depressive disorder and depressive symptomatology as predictors of husband to wife physical aggression. Violence and Victims; 13: 347-60.

Freud S (1917) Mourning and melancholia. In The Standard Edition of the Complete Psychological Works of Sigmund Freud, Volume 14 (ed J Strachey): 239-58. Hogarth Press, 1953.

\begin{tabular}{|lllll|}
\hline \multicolumn{4}{|c}{ MCO answers } \\
1 & 2 & 3 & 4 & 5 \\
af & af & af & af & at \\
bf & bf & bt & bf & bf \\
cf & ct & cf & ct & cf \\
dt & df & df & df & df \\
ef & ef & ef & ef & ef
\end{tabular}


Gabbard G0 (2000) Psychodynamic Psychiatry in Clinical Practice (3rd edn). American Psychiatric Press.

Goldman L, Haaga DAF (1995) Depression and the experience and expression of anger in marital and other relationships. Journal of Nervous and Mental Disease; 183: 505-9.

Jacobson E (1954) Transference problems in the psychoanalytic treatment of severely depressed patients. Journal of the American Psychoanalytic Association: 2: 695-705.

Jacobson E (1971) Depression: Comparative Studies of Normal, Neurotic, and Psychotic Conditions. International Universities Press.

Jacobson E (1975) The psychoanalytic treatment of depressive patients. In Depression and Human Existence (ed B Anthony): 431-43. Little, Brown $\&$ Co

Klein M (1935) A contribution to the psychogenesis of manic depressive states. International Journal of Psychoanalysis; 16: 145-74.

Klein M (1940) Mourning and its relation to manic-depressive states, in love. In Guilt and Reparation and Other Works 1921-1945, 344-69. Free Press, 1975.

Knekt P, Lindfors 0, Harkanen T, et al (2008) Randomized trial on the effectiveness of long-and short-term psychodynamic psychotherapy and solution-focused therapy on psychiatric symptoms during a 3-year followup. Psychological Medicine; 38: 689-703.

Koh KB, Kim CH, Park JK (2002) Predominance of anger in depressive disorders compared with anxiety disorders and somatoform disorders. Journal of Clinical Psychiatry; 63: 486-92.

Kuyken W, Watkins E, Beck AT (2005) Cognitive-behaviour therapy for mood disorders. In Oxford Textbook of Psychotherapy (eds GO Gabbard, JS Beck, J Holmes): 111-26. Oxford University Press.
Leichsenring $F$ (2001) Comparative effects of short-term psychodynamic psychotherapy and cognitive-behavioural therapy in depression: a metaanalytic approach. Clinical Psychology Review; 21: 401-19.

Luutonen S (2007) Anger and depression - theoretical and clinical considerations. Nordic Journal of Psychiatry; 61: 246-51.

Milrod BL, Busch FN, Cooper AM, et al (1997) Manual of Panic-Focused Psychodynamic Psychotherapy. American Psychiatric Press.

Milrod B, Leon AC, Busch FN, et al (2007) A randomized controlled clinical trial of psychoanalytic psychotherapy for panic disorder. American Journal of Psychiatry; 164: 265-72

Pan H, Neidig P, O'Leary D (1994) Predicting mild to severe husband to wife physical aggression. Journal of Consulting and Clinical Psychology, 62: $975-81$.

Rado S (1928) The problem of melancholia. International Journal of Psychoanalysis; 9: 420-38

Rudden MG, Busch FN, Milrod BL, et al (2003) Panic disorder and depression: a psychodynamic exploration of comorbidity. International Journal of Psychoanalysis; 84: 997-1015

Schless AP, Mendels J, Kipperman A, et al (1974) Depression and hostility. Journal of Nervous Mental Disease; 159: 91-100.

Schuyler D (2003) Cognitive therapy for depression. Primary Psychiatry; 10: 33-6.

Swanson JW, Holzer CE, Ganju VK, et al (1990) Violence and psychiatric disorder in the community: evidence from the Epidemiologic Catchment Area surveys. Hospital and Community Psychiatry; 41: 61-70.

Wolfersdorf M, Kiefer A (1998) Depression and aggression. A control group study on the aggression hypothesis in depressive disorders based on the Buss Durkee Questionnaire. Psychiatrische Praxis; 25: 240-5.
MCQs

1 Research studies on anger and depression indicate that:

a people with depression direct anger only inwards

b people with depression direct anger only outwards

c people with depression typically do not have problems with anger

d people with depression may struggle with anger in different ways

e anger is irrelevant to depression.

2 In linking anger and depression, psychoanalytic theorists have postulated that:

a patients are always consciously aware of their anger

b depression develops from beliefs and anger plays a minimal role

c patients struggle with conflicts about their anger, leading to guilt and self-criticism d depression stems entirely from a 'chemical imbalance'

e therapists' should not address patients' anger for fear of exacerbating their conflicts.

3 A defence mechanism that is frequently employed by patients with depression to cope with angry feelings is:

a humour

b denial

c displacement

d acting out

e sublimation.

4 According to a psychodynamic model of depression, conflicts about anger:

a typically do not affect interpersonal relationships

b make it impossible to have interpersona relationships c often lead patients to be unassertive and submissive in relationships

$\mathrm{d}$ are unrelated to low self-esteem

e do not emerge in the relationship with the therapist

5 In psychodynamic approaches to depression:

a it is essential that the therapist responds to the patient's anger in a non-judgemental manner

b the therapist criticises the patient's anger, to reduce it with negative feedback

c the therapist ignores any expression or fantasy of anger that the patient shows towards them

$\mathrm{d}$ the therapist suggests that anger and depression are primarily chemically based

e the therapist focuses on the patient's problematic beliefs 